\title{
EXTENSION OF THE SOUTHERN HEMISPHERE ATMOSPHERIC RADIOCARBON CURVE, 2120-850 YEARS BP: RESULTS FROM TASMANIAN HUON PINE
}

\author{
Susan Zimmerman ${ }^{1,2} \cdot$ Thomas Guilderson ${ }^{1,3} \cdot$ Brendan Buckley $^{4}$ Edward Cook ${ }^{4}$ \\ ABSTRACT. Decadal samples of dendrochronologically dated pine (Lagorostrobos franklinii) from the Stanley River basin, \\ Tasmania, have been radiocarbon dated between $2120-850 \mathrm{yr}$ BP. This data set overlaps and extends the current Southern \\ Hemisphere record, which covers the period 110-995 yr BP. There is good agreement between the 2 records between 995- \\ $850 \mathrm{yr}$ BP, between sample replicates and with consensus values for standards. As in the younger data set, we find evidence \\ for a distinct but variable offset between the Southern Hemisphere data and IntCal04; although this is likely due to real tem- \\ poral variability in the interhemispheric offset, further work is planned to rule out possible laboratory or sample preparation \\ differences.
}

\section{INTRODUCTION}

Radiocarbon dating is the most widespread method of dating geological and archaeological materials from the late Quaternary period (last $\sim 50 \mathrm{ka}$ ) but has inherent difficulties. Because the ${ }^{14} \mathrm{C} /{ }^{12} \mathrm{C}$ ratio of the atmosphere has not remained constant, nullifying a fundamental tenet of radiometric dating, a ${ }^{14} \mathrm{C}$ date may not equate one-to-one with a single calendar year, and must be calibrated. Calibration has been achieved for the last 12,400 yr using a continuous series of dendrochronologically dated tree rings, all from the Northern Hemisphere. Fluctuations in atmospheric ${ }^{14} \mathrm{C}$ are primarily caused by changes in production rate due to solar and geomagnetic variability, but may also result from changes in storage and release of carbon from various reservoirs, including circulation changes in the ocean.

Ocean circulation in combination with the net air-sea exchange of carbon dioxide in the 2 hemispheres has been reasonably hypothesized to influence the ${ }^{14} \mathrm{C}$ content of the respective hemispheres. Excess efflux of subatmospheric ${ }^{14} \mathrm{CO}_{2}$ from the ocean should increase the ${ }^{14} \mathrm{C}$ age of the Southern Hemisphere relative to that of the Northern. For example, Vogel et al. (1993) found an average Southern Hemisphere offset of $41 \pm 5 \mathrm{yr}$ over the 19th century in South Africa, while Stuiver and Braziunas (1998) reported an offset of $23 \pm 9 \mathrm{yr}$ in Chilean wood over the 19th century and $38 \pm 5 \mathrm{yr}$ between AD 1670-1722, demonstrating apparent variability in the offset. The results of McCormac et al. (1998) also emphasized the variability of the offset in New Zealand and Irish wood between AD 1725-1895, with the Southern Hemisphere wood $27 \pm 5$ yr older on average.

Recently, results of an impressive cross-laboratory, interhemispheric comparison by the Waikato and Belfast laboratories (Hogg et al. 2002; McCormac et al. 2002) showed with very high precision that the atmosphere in the Southern Hemisphere was on average $41 \pm 14 \mathrm{yr}$ older than in the Northern Hemisphere over the period AD 955-1840. However, the offset varied from 8 to $80 \mathrm{yr}$, and showed an apparent periodicity of $\sim 120 \mathrm{yr}$. Because there is no reason to assume that the carbon cycle or oceanographic changes that apparently drive the interhemispheric offset remain stable or can be predicted a priori, calibration with a local dendrochronologically dated ${ }^{14} \mathrm{C}$ curve is the most robust method of calibrating Southern Hemisphere ${ }^{14} \mathrm{C}$ dates. Here, we present preliminary results of decadal samples from Huon pine collected from the Stanley River basin, Tasmania, covering the period 2120-850 cal yr BP (170 BC-AD 1100).

\footnotetext{
${ }^{1}$ Center for Accelerator Mass Spectrometry, Lawrence Livermore National Laboratory, Livermore, California 94550, USA ${ }^{2}$ Corresponding author. Email: zimmerman17@1lnl.gov.

${ }^{3}$ Dept. of Ocean Sciences and Institute of Marine Sciences, University of California, Santa Cruz, California 94064, USA.

${ }^{4}$ Tree-Ring Laboratory of the Lamont Doherty Earth Observatory, Palisades, New York 10964, USA.
} 


\section{METHODS}

Two specimens of subfossil Huon pine (Lagorostrobos franklinii) were recovered from the Stanley River in the northwest highlands of Tasmania. Specimen SRT 440A contains $\sim 1100$ rings, spanning the period $2130-1030 \mathrm{cal} \mathrm{yr} \mathrm{BP} \mathrm{(180} \mathrm{BC} \mathrm{to} \mathrm{AD} \mathrm{920),} \mathrm{and} \mathrm{specimen} \mathrm{SRT} \mathrm{44a} \mathrm{contains} ~ 724$ rings, spanning 1550 to 826 cal yr BP (AD 400 to 1124). Both specimens are well preserved and consistently banded, and dendrochronologically dated within a well-established master framework (Buckley et al. 1997).

Decadal samples were manually milled using a Dremel ${ }^{\circledR}$ drill at slow speed with a carbide burr, yielding $\sim 10 \mathrm{mg}$ of raw material. The raw material was chemically pretreated with a modified deVries treatment $\left(1 \mathrm{~N} \mathrm{HCl}, 1 \mathrm{~N} \mathrm{NaOH}\right.$ [until clear, at least $2 \times$ ], $1 \mathrm{~N} \mathrm{HCl}$, all at $\left.90^{\circ} \mathrm{C}\right)$, rinsed copiously with Milli-Q ${ }^{\mathrm{TM}}$ water, and dried overnight on a heating block. Aliquots $(\sim 1.5-2 \mathrm{mg})$ of the pretreated material were sealed in evacuated quartz tubes containing copper oxide and silver and combusted at $900{ }^{\circ} \mathrm{C}$. The resulting $\mathrm{CO}_{2}$ was cryogenically purified, transferred to individual graphitization reactors, and reduced to elemental carbon in the presence of iron catalyst and a stoichiometric excess of hydrogen (Vogel et al. 1984). The graphite-iron mixture was then pressed into individual aluminum target holders and measured via accelerator mass spectrometry (AMS) at CAMS.

Individual targets were cycled in a prescribed sequence to attain $\sim 300-500 \mathrm{k}{ }^{14} \mathrm{C}$ counts in 50,000 counts per acquisition cycle. Data are normalized to the OXI oxalic acid standard (J Southon, unpublished data) and reported as conventional ${ }^{14} \mathrm{C}$ age according to Stuiver and Polach (1977). Background correction is facilitated by the analysis of similarly pretreated and prehandled ${ }^{14} \mathrm{C}$-free wood, QL-4766, a wood sample shown to be of infinite age at the University of Washington laboratory. Sample-specific $\delta^{13} \mathrm{C}$ values (relative to V-PDB) were measured via continuous-flow isotope ratio mass spectrometry at the Stanford Isotope Laboratory, on $\sim 0.8-\mathrm{mg}$ splits of the pretreated wood.

The accuracy of our results was monitored using a sample of alpha-cellulose provided by the Belfast laboratory, which was pretreated with $1 \mathrm{~N} \mathrm{HCl}$ and rinsed with Milli-Q water prior to conversion to graphite. We assessed the precision of our data with measurement of replicate unknowns and repeated measurement of an Irish oak sample, Q1323, previously measured at Belfast. Three years of the oak sample were milled and pretreated exactly the same as the Huon pine samples, and measured repeatedly with each batch of unknowns.

\section{RESULTS}

Figure 1 shows the result of 99 replicate analyses, of which $63 \%$ overlap the 1- $\sigma$ analytical uncertainties. For samples with 2 or more measurements, the reported value is a weighted mean. The means of measurements on the Belfast cellulose, Q1323, and QL-4766 are given in Table 1. The alpha-cellulose, dendrochronologically dated at $1510 \mathrm{BC}$, has a ${ }^{14} \mathrm{C}$ age of $3247 \pm 22$ (G McCormac, personal communication), which corresponds well with our ${ }^{14} \mathrm{C}$ age of $3243 \pm 34$ (Table 1). The Irish oak, Q1323, was used to monitor the entire sample preparation procedure, and yields a standard deviation of $26 \mathrm{yr}(n=18)$. Note that our measured age is on $3 \mathrm{yr}$ of a bidecadal sample and thus is not comparable to the age published by Pearson et al. (1986). The Huon data overlap the published Wk-Qub data for the period $995-855 \mathrm{BP}$, a total of 15 decadal samples. The 3 data sets show reasonable agreement (Figure 2), overlapping at $1 \sigma$. 


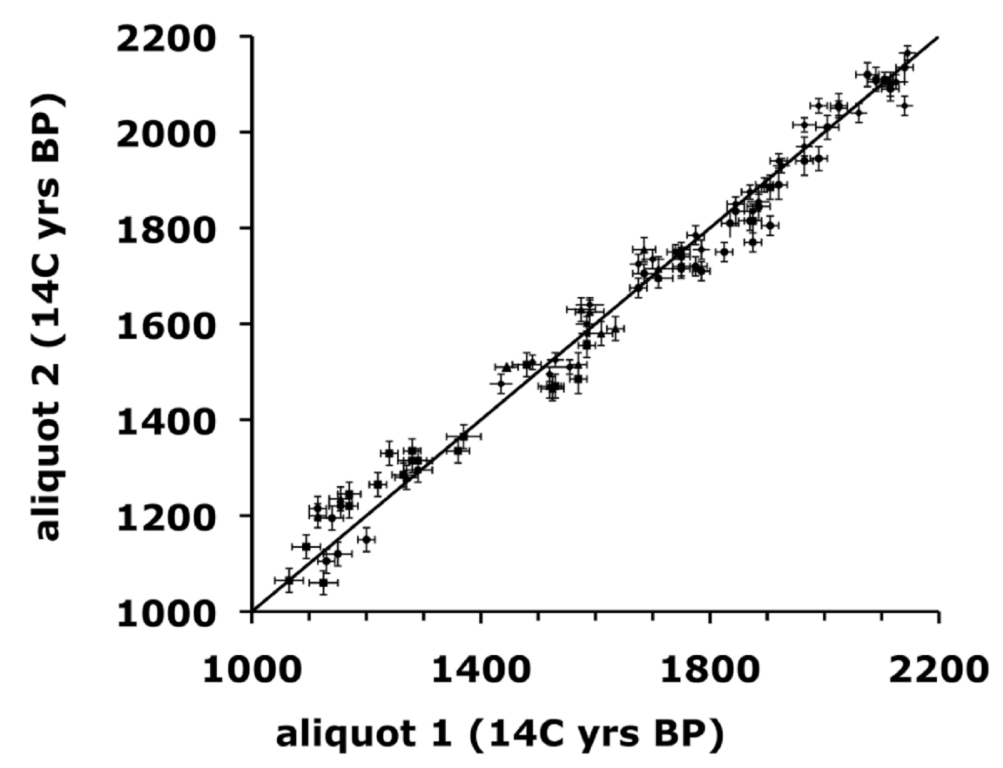

Figure 1 Comparison of results for complete- process replicates made on selected samples $(n=99)$ included in this study. Error bars on data points represent $1-\sigma$ analytical error.

Table 1 Process standard and blank $\left({ }^{14} \mathrm{C}\right.$-free wood $)$ prepared and analyzed simultaneously with the SRT sample sequence. Dates are given in yr BP.

\begin{tabular}{llccl}
\hline Sample & $n$ & Mean (yr BP) & Standard dev & Reported value (yr BP) \\
\hline BelCell & 11 & 3243 & 34 & $3247 \pm 22$ \\
Q1323 & 18 & 4132 & 26 & $4199 \pm 12$ \\
QL-4766 & 14 & 50,894 & 1760 & - \\
\hline
\end{tabular}

${ }^{\mathrm{a}} \mathrm{Q} 1323$ is a bidecadal sample that was kindly provided by the Qub lab. Because only $3 \mathrm{yr}$ of the Q1323 sample were milled, processed, and analyzed, our analyses of the Q1323 wood are not comparable to the result given by Pearson et al. (1986).

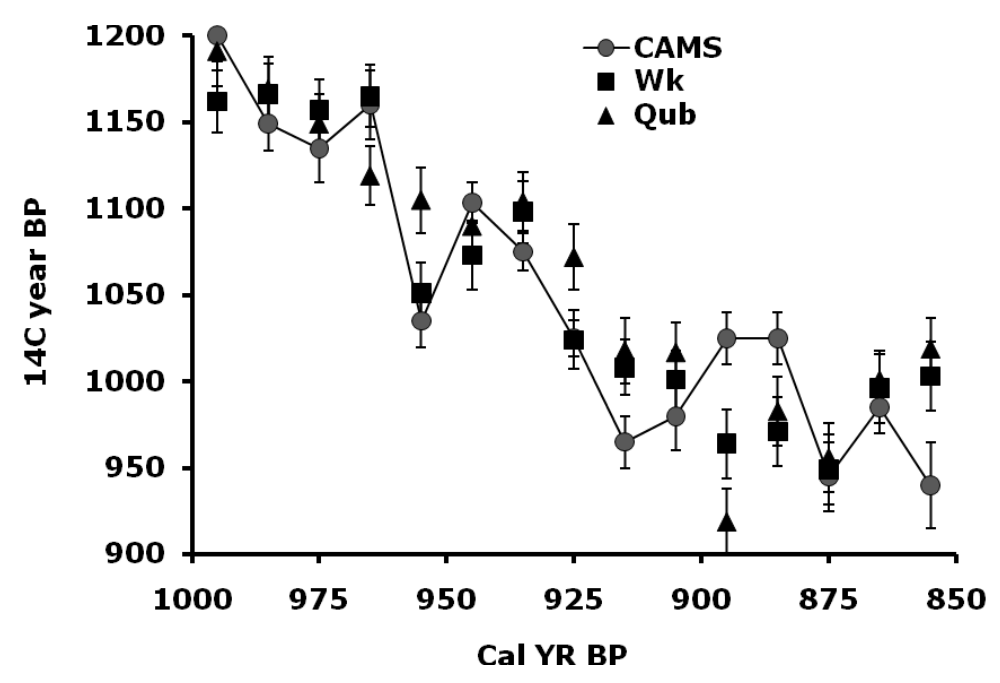

Figure 2 Overlap interval between this study and data of Hogg et al. (2002). With few exceptions, the Huon pine between 995-955 yr BP reported here agrees within 1- $\sigma$ error with measurements made at the Waikato (Wk) and Belfast $(\mathrm{Qub})$ laboratories. 


\section{DISCUSSION}

The Huon pine data (Table 2) show a similar structure to the IntCal04 curve (Reimer et al. 2004), but are generally older (Figure 3), almost certainly because the latter is composed of Northern Hemisphere data. Two brief periods show no offset, in particular from 1095-1175 BP, and bear further examination to reproduce this result. The average offset between the new data and IntCal04 is $42 \pm$ $26 \mathrm{yr}$, indicating relatively large variability (Table 3 ).

Table 2 Measurements on decadal samples of Huon pine (Lagorostrobos franklinii) collected in the Stanley River basin, Tasmania. Left-hand column ( $n$ ) gives the number of replicates measured for each decade; for $n>1,{ }^{14} \mathrm{C}$ age reported is a weighted mean. Dendro age is according to master chronology developed by Buckley et al. (1997); analytical precision on $\delta^{13} \mathrm{C}$ is $0.1 \%$.

\begin{tabular}{|c|c|c|c|c|c|c|c|}
\hline \multirow[b]{2}{*}{$n$} & \multirow[b]{2}{*}{ Sample ID } & \multirow{2}{*}{$\begin{array}{l}\delta^{13} \mathrm{C} \\
(\%)\end{array}$} & \multirow[b]{2}{*}{ Dendro age } & \multicolumn{2}{|c|}{ Mid-point } & \multirow{2}{*}{$\begin{array}{l}{ }^{14} \mathrm{C} \text { age } \\
\text { (yr BP) }\end{array}$} & \multirow[b]{2}{*}{ \pm} \\
\hline & & & & $\mathrm{BC} / \mathrm{AD}$ & cal yr BP & & \\
\hline 1 & Z9 & -24.97 & $161-170 \mathrm{BC}$ & -165 & 2115 & 2170 & 15 \\
\hline 1 & Z8 & -24.56 & $151-160 \mathrm{BC}$ & -155 & 2105 & 2160 & 15 \\
\hline 2 & G8 & -25.82 & $140-150 \mathrm{BC}$ & -145 & 2095 & 2130 & 11 \\
\hline 1 & $\mathrm{Z7}$ & -23.81 & $131-140 \mathrm{BC}$ & -135 & 2085 & 2150 & 15 \\
\hline 2 & G7 & -24.07 & $120-130 \mathrm{BC}$ & -125 & 2075 & 2123 & 11 \\
\hline 2 & Z6 & -23.97 & $111-120 \mathrm{BC}$ & -115 & 2065 & 2165 & 11 \\
\hline 3 & G6 & -23.72 & $100-110 \mathrm{BC}$ & -105 & 2055 & 2115 & 9 \\
\hline 1 & $\mathrm{Z5}$ & -23.49 & $91-100 \mathrm{BC}$ & -95 & 2045 & 2135 & 15 \\
\hline 3 & G5 & -24.56 & $80-90$ BC & -85 & 2035 & 2105 & 9 \\
\hline 3 & Z4 & -24.21 & $71-80 \mathrm{BC}$ & -75 & 2025 & 2122 & 11 \\
\hline 2 & G4 & -23.78 & $60-70 \mathrm{BC}$ & -65 & 2015 & 2114 & 12 \\
\hline 2 & $\mathrm{Z3}$ & -24.07 & $51-60 \mathrm{BC}$ & -55 & 2005 & 2113 & 11 \\
\hline 3 & G3 & -23.82 & $40-50 \mathrm{BC}$ & -45 & 1995 & 2052 & 9 \\
\hline 2 & $\mathrm{Z2}$ & -24.40 & $31-40 \mathrm{BC}$ & -35 & 1985 & 2013 & 12 \\
\hline 3 & $\mathrm{G} 2$ & -24.33 & $20-30 \mathrm{BC}$ & -25 & 1975 & 2002 & 9 \\
\hline 1 & Z1 & -23.51 & $11-20 \mathrm{BC}$ & -15 & 1965 & 2040 & 15 \\
\hline 1 & G1 & -23.64 & $10 \mathrm{BC}-\mathrm{AD} 0$ & -5 & 1955 & 2040 & 15 \\
\hline 2 & $\mathrm{Z10}$ & -23.37 & AD 1-10 & 5 & 1945 & 2068 & 12 \\
\hline 1 & G9 & -24.04 & AD 10-20 & 15 & 1935 & 2055 & 15 \\
\hline 1 & Z11 & -23.81 & AD 21-30 & 25 & 1925 & 2025 & 15 \\
\hline 1 & G10 & -22.78 & AD $30-40$ & 35 & 1915 & 1995 & 15 \\
\hline 1 & Z12 & -22.80 & AD $41-50$ & 45 & 1905 & 2015 & 15 \\
\hline 2 & G11 & -23.11 & AD 50-60 & 55 & 1895 & 2012 & 12 \\
\hline 1 & Z13 & -22.99 & AD $61-70$ & 65 & 1885 & 1975 & 20 \\
\hline 1 & G12 & -23.73 & AD 70-80 & 75 & 1875 & 1950 & 20 \\
\hline 2 & Z14 & -23.45 & AD 81-90 & 85 & 1865 & 1940 & 11 \\
\hline 2 & G13 & -23.58 & AD 90-100 & 95 & 1855 & 1940 & 11 \\
\hline 3 & Z15 & -23.72 & AD $101-110$ & 105 & 1845 & 1973 & 11 \\
\hline 1 & G14 & -23.85 & AD $110-120$ & 115 & 1835 & 1945 & 15 \\
\hline 1 & Z16 & -22.37 & AD $121-130$ & 125 & 1825 & 1890 & 15 \\
\hline 2 & G15 & -22.32 & AD $130-140$ & 135 & 1815 & 1895 & 11 \\
\hline 1 & Z17 & -22.49 & AD $141-150$ & 145 & 1805 & 1875 & 15 \\
\hline 1 & G16 & -22.73 & AD $150-160$ & 155 & 1795 & 1865 & 20 \\
\hline 3 & Z18 & -22.81 & AD $161-170$ & 165 & 1785 & 1883 & 9 \\
\hline 1 & G17 & -22.87 & AD $170-180$ & 175 & 1775 & 1850 & 15 \\
\hline 2 & Z19 & -22.86 & AD 181-190 & 185 & 1765 & 1929 & 13 \\
\hline 2 & G18 & -23.63 & AD 190-200 & 195 & 1755 & 1905 & 11 \\
\hline
\end{tabular}


Table 2 Measurements on decadal samples of Huon pine (Lagorostrobos franklinii) collected in the Stanley River basin, Tasmania. Left-hand column $(n)$ gives the number of replicates measured for each decade; for $n>1,{ }^{14} \mathrm{C}$ age reported is a weighted mean. Dendro age is according to master chronology developed by Buckley et al. (1997); analytical precision on $\delta^{13} \mathrm{C}$ is $0.1 \%$. (Continued)

\begin{tabular}{|c|c|c|c|c|c|c|c|}
\hline \multirow[b]{2}{*}{$n$} & \multirow[b]{2}{*}{ Sample ID } & \multirow{2}{*}{$\begin{array}{l}\delta^{13} \mathrm{C} \\
(\%)\end{array}$} & \multirow[b]{2}{*}{ Dendro age } & \multicolumn{2}{|c|}{ Mid-point } & \multirow{2}{*}{$\begin{array}{l}{ }^{14} \mathrm{C} \text { age } \\
\text { (yr BP) }\end{array}$} & \multirow[b]{2}{*}{ \pm} \\
\hline & & & & $\mathrm{BC} / \mathrm{AD}$ & cal yr BP & & \\
\hline 3 & $\mathrm{Z} 20$ & -23.54 & AD 201-210 & 205 & 1745 & 1880 & 9 \\
\hline 3 & G19 & -23.18 & AD $210-220$ & 215 & 1735 & 1861 & 10 \\
\hline 2 & Z21 & -22.98 & AD $221-230$ & 225 & 1725 & 1852 & 12 \\
\hline 2 & G20 & -23.02 & AD $230-240$ & 235 & 1715 & 1846 & 13 \\
\hline 4 & Z22 & -23.01 & AD $241-250$ & 245 & 1705 & 1848 & 8 \\
\hline 3 & G21 & -23.46 & AD $250-260$ & 255 & 1695 & 1750 & 9 \\
\hline 2 & $\mathrm{Z} 23$ & -21.96 & AD $261-270$ & 265 & 1685 & 1765 & 12 \\
\hline 3 & G22 & -22.13 & AD $270-280$ & 275 & 1675 & 1760 & 9 \\
\hline 3 & $\mathrm{Z} 24$ & -21.51 & AD $281-290$ & 285 & 1665 & 1779 & 9 \\
\hline 2 & G23 & -21.94 & AD $290-300$ & 295 & 1655 & 1773 & 11 \\
\hline 2 & $\mathrm{Z} 25$ & -21.82 & AD $301-310$ & 305 & 1645 & 1825 & 12 \\
\hline 2 & G24 & -21.71 & AD $310-320$ & 315 & 1635 & 1804 & 12 \\
\hline 1 & Z26 & -22.13 & AD $321-330$ & 325 & 1625 & 1805 & 15 \\
\hline 1 & G25 & -21.61 & AD $330-340$ & 335 & 1615 & 1805 & 15 \\
\hline 3 & $\mathrm{Z} 27$ & -23.06 & AD $341-350$ & 345 & 1605 & 1738 & 10 \\
\hline 2 & G26 & -23.24 & AD $350-360$ & 355 & 1595 & 1760 & 11 \\
\hline 3 & Z28 & -22.11 & AD $361-370$ & 365 & 1585 & 1709 & 9 \\
\hline 1 & G27 & -22.08 & AD $370-380$ & 375 & 1575 & 1715 & 15 \\
\hline 2 & Z29 & -23.61 & AD 380-390 & 385 & 1565 & 1715 & 11 \\
\hline 1 & G28 & -23.97 & AD 390-400 & 395 & 1555 & 1680 & 15 \\
\hline 2 & $\mathrm{Z30}$ & -22.56 & $\mathrm{AD} 401-410$ & 405 & 1545 & 1738 & 14 \\
\hline 1 & Z31 & -22.25 & $\mathrm{AD} 411-420$ & 415 & 1535 & 1695 & 20 \\
\hline 1 & Z32 & -22.42 & $\mathrm{AD} 421-430$ & 425 & 1525 & 1675 & 20 \\
\hline 3 & Z33 & -21.79 & AD $431-440$ & 435 & 1515 & 1651 & 10 \\
\hline 1 & Z34 & -21.81 & $\mathrm{AD} 441-450$ & 445 & 1505 & 1625 & 20 \\
\hline 1 & $\mathrm{Z35}$ & -22.17 & $\mathrm{AD} 451-460$ & 455 & 1495 & 1635 & 20 \\
\hline 2 & Z36 & -22.03 & $\mathrm{AD} 461-470$ & 465 & 1485 & 1638 & 11 \\
\hline 2 & Z37 & -22.65 & $\mathrm{AD} 471-480$ & 475 & 1475 & 1623 & 11 \\
\hline 1 & Z38 & -22.31 & AD $481-490$ & 485 & 1465 & 1645 & 20 \\
\hline 2 & Z39 & -22.50 & $\mathrm{AD} 491-500$ & 495 & 1455 & 1615 & 12 \\
\hline 2 & $\mathrm{Z} 40$ & -22.54 & AD 501-510 & 505 & 1445 & 1611 & 12 \\
\hline 1 & Z41 & -22.45 & AD 511-520 & 515 & 1435 & 1665 & 15 \\
\hline 2 & Z42 & -22.58 & AD 521-530 & 525 & 1425 & 1603 & 11 \\
\hline 1 & Z43 & -22.57 & AD 531-540 & 535 & 1415 & 1605 & 15 \\
\hline 2 & Z44 & -21.94 & AD 541-550 & 545 & 1405 & 1568 & 11 \\
\hline 2 & $\mathrm{Z} 45$ & -22.16 & AD 551-560 & 555 & 1395 & 1549 & 12 \\
\hline 1 & Z46 & -22.25 & AD 561-570 & 565 & 1385 & 1560 & 20 \\
\hline 2 & Z47 & -21.79 & AD 571-580 & 575 & 1375 & 1564 & 12 \\
\hline 3 & Z48 & -22.54 & AD 581-590 & 585 & 1365 & 1535 & 9 \\
\hline 1 & Z49 & -22.03 & AD 591-600 & 595 & 1355 & 1495 & 15 \\
\hline 1 & $\mathrm{Z} 50$ & -22.10 & AD $601-610$ & 605 & 1345 & 1480 & 20 \\
\hline 2 & Z51 & -21.89 & AD $611-620$ & 615 & 1335 & 1480 & 14 \\
\hline 4 & $\mathrm{Z} 57$ & -23.45 & AD $621-630$ & 625 & 1325 & 1508 & 8 \\
\hline 1 & Z58 & -21.63 & AD $631-640$ & 635 & 1315 & 1500 & 20 \\
\hline 1 & Z59 & -22.33 & AD $641-650$ & 645 & 1305 & 1440 & 15 \\
\hline
\end{tabular}


Table 2 Measurements on decadal samples of Huon pine (Lagorostrobos franklinii) collected in the Stanley River basin, Tasmania. Left-hand column $(n)$ gives the number of replicates measured for each decade; for $n>1,{ }^{14} \mathrm{C}$ age reported is a weighted mean. Dendro age is according to master chronology developed by Buckley et al. (1997); analytical precision on $\delta^{13} \mathrm{C}$ is $0.1 \%$. (Continued)

\begin{tabular}{|c|c|c|c|c|c|c|c|}
\hline \multirow[b]{2}{*}{$n$} & \multirow[b]{2}{*}{ Sample ID } & \multirow{2}{*}{$\begin{array}{l}\delta^{13} \mathrm{C} \\
(\% 0)\end{array}$} & \multirow[b]{2}{*}{ Dendro age } & \multicolumn{2}{|c|}{ Mid-point } & \multirow{2}{*}{$\begin{array}{l}{ }^{14} \mathrm{C} \text { age } \\
\text { (yr BP) }\end{array}$} & \multirow[b]{2}{*}{ \pm} \\
\hline & & & & $\mathrm{BC} / \mathrm{AD}$ & cal yr BP & & \\
\hline 2 & Z60 & -21.91 & AD $651-660$ & 655 & 1295 & 1391 & 13 \\
\hline 1 & Z61 & -22.42 & AD 661-670 & 665 & 1285 & 1405 & 15 \\
\hline 2 & Z62 & -21.68 & AD 671680 & 675 & 1275 & 1378 & 14 \\
\hline 2 & Z63 & -22.30 & AD 681-690 & 685 & 1265 & 1326 & 13 \\
\hline 2 & Z64 & -21.31 & AD $691-700$ & 695 & 1255 & 1310 & 12 \\
\hline 1 & Z65 & -22.21 & AD 701-710 & 705 & 1245 & 1335 & 20 \\
\hline 1 & Z66 & -22.04 & AD 711-720 & 715 & 1235 & 1315 & 15 \\
\hline 1 & Z67 & -21.60 & AD 721-730 & 725 & 1225 & 1305 & 20 \\
\hline 2 & Z68 & -21.73 & AD 731-740 & 735 & 1215 & 1303 & 12 \\
\hline 2 & Z69 & -21.73 & AD 741-750 & 745 & 1205 & 1301 & 12 \\
\hline 3 & $\mathrm{Z70}$ & -23.57 & AD 751-760 & 755 & 1195 & 1323 & 9 \\
\hline 4 & Z71 & -23.66 & AD 761-770 & 765 & 1185 & 1316 & 9 \\
\hline 2 & Z72 & -24.41 & AD 771-780 & 775 & 1175 & 1200 & 11 \\
\hline 3 & Z73 & -22.97 & AD 781-790 & 785 & 1165 & 1229 & 10 \\
\hline 1 & $\mathrm{Z} 74$ & -23.63 & AD 791-800 & 795 & 1155 & 1195 & 15 \\
\hline 2 & Z75 & -23.70 & AD $801-810$ & 805 & 1145 & 1253 & 11 \\
\hline 2 & Z76 & -22.49 & AD 811-820 & 815 & 1135 & 1238 & 12 \\
\hline 1 & Z77 & -22.85 & AD $821-830$ & 825 & 1125 & 1190 & 15 \\
\hline 1 & Z78 & -22.57 & AD $831-840$ & 835 & 1115 & 1215 & 15 \\
\hline 1 & Z79 & -22.05 & AD $841-850$ & 845 & 1105 & 1205 & 20 \\
\hline 1 & Z80 & -22.43 & AD $851-860$ & 855 & 1095 & 1175 & 25 \\
\hline 1 & Z81 & -22.42 & AD $861-870$ & 865 & 1085 & 1225 & 15 \\
\hline 2 & Z82 & -22.77 & AD $871-880$ & 875 & 1075 & 1195 & 12 \\
\hline 3 & Z83 & -22.20 & AD $881-890$ & 885 & 1065 & 1200 & 9 \\
\hline 2 & Z84 & -22.72 & AD 891-900 & 895 & 1055 & 1195 & 11 \\
\hline 2 & Z85 & -22.39 & AD 901-910 & 905 & 1045 & 1140 & 11 \\
\hline 1 & Z86 & -21.92 & AD 911-920 & 915 & 1035 & 1140 & 20 \\
\hline 1 & Z87 & -21.67 & AD 921-930 & 925 & 1025 & 1185 & 20 \\
\hline 2 & Z88 & -21.69 & AD 931-940 & 935 & 1015 & 1163 & 11 \\
\hline 1 & Z89 & -21.89 & AD 941-950 & 945 & 1005 & 1180 & 15 \\
\hline 1 & Z90 & -21.72 & AD 951-960 & 955 & 995 & 1200 & 15 \\
\hline 2 & Z91 & -21.50 & AD 961-970 & 965 & 985 & 1149 & 16 \\
\hline 1 & Z92 & -22.05 & AD 971-980 & 975 & 975 & 1135 & 20 \\
\hline 1 & Z93 & -21.40 & AD 981-990 & 985 & 965 & 1160 & 20 \\
\hline 1 & Z94 & -23.34 & AD 991-1000 & 995 & 955 & 1035 & 15 \\
\hline 2 & Z95 & -22.85 & AD 1001-1010 & 1005 & 945 & 1103 & 12 \\
\hline 2 & Z96 & -23.81 & AD 1011-1020 & 1015 & 935 & 1075 & 11 \\
\hline 2 & Z97 & -23.13 & AD 1021-1030 & 1025 & 925 & 1025 & 11 \\
\hline 1 & Z98 & -22.54 & AD 1031-1040 & 1035 & 915 & 965 & 15 \\
\hline 1 & Z99 & -20.96 & AD 1041-1050 & 1045 & 905 & 980 & 20 \\
\hline 1 & $\mathrm{Z} 100$ & -21.07 & AD 1051-1060 & 1055 & 895 & 1025 & 15 \\
\hline 1 & Z101 & -21.32 & AD 1061-1070 & 1065 & 885 & 1025 & 15 \\
\hline 1 & Z102 & -21.73 & AD $1071-1080$ & 1075 & 875 & 945 & 20 \\
\hline 1 & Z103 & -23.25 & AD 1081-1090 & 1085 & 865 & 985 & 15 \\
\hline 1 & Z104 & -22.79 & AD 1091-1100 & 1095 & 855 & 940 & 25 \\
\hline
\end{tabular}




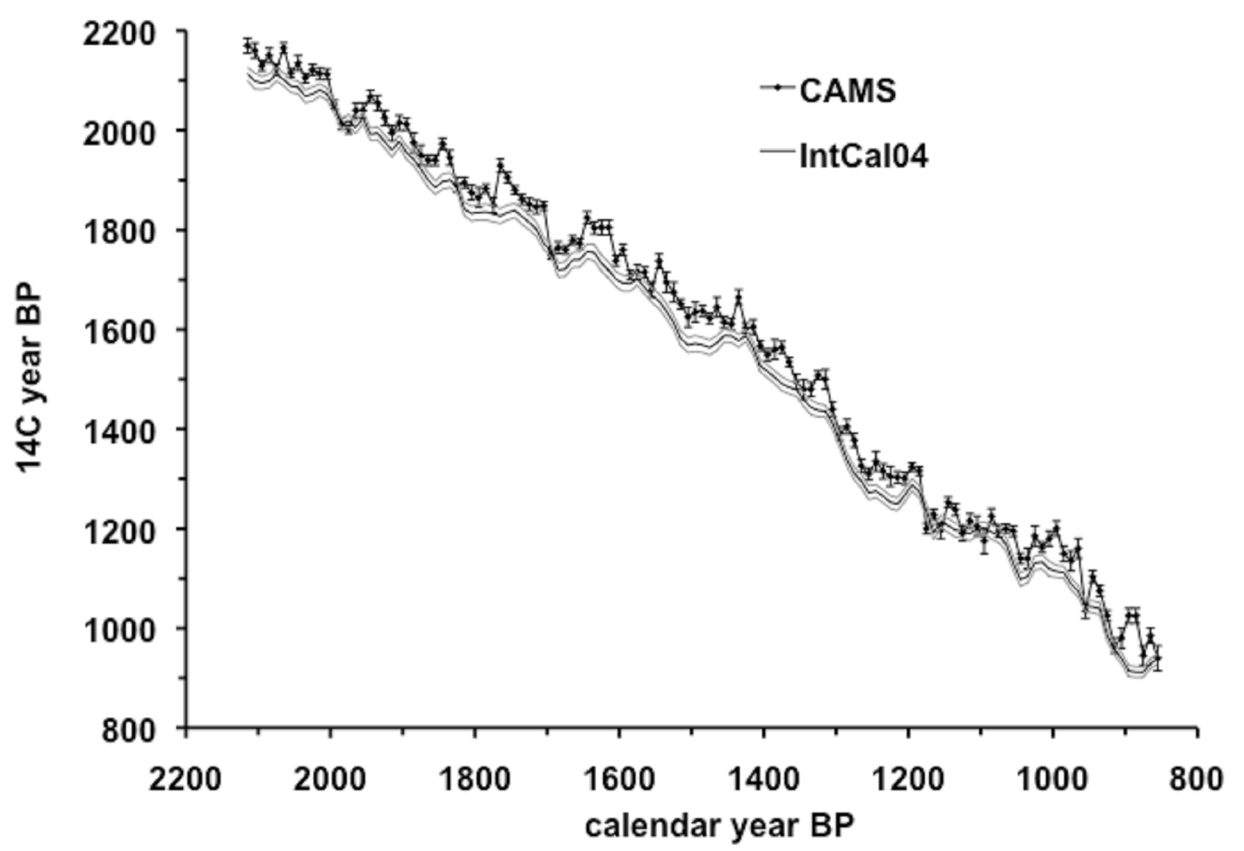

Figure 3 Stanley River Huon pine results plotted with IntCal04 (Reimer et al. 2004)

Table 3 Comparison of average offset for Southern Hemisphere data sets measured at Queen's University Belfast (Qub), Waikato (Wk) (both Hogg et al. 2002), and CAMS (this study) with IntCal04 (Reimer et al. 2004). Despite covering different time intervals, the Southern Hemisphere data sets show consistent magnitude and variability of offset. All units are years.

\begin{tabular}{llll}
\hline & CAMS & Wk & Qub \\
\hline $\max$ & 113 & 91 & 98 \\
$\min$ & -35 & -7 & -9 \\
avg & 42 & 47 & 44 \\
std dev & 26 & 17 & 25 \\
\hline
\end{tabular}

Our observation of a distinct but variable offset between Tasmania and IntCal04 is coherent with a comparison of the published New Zealand data and IntCal04; indeed, the offsets are nearly identical (Table 3), both in magnitude and variability. These results support the previous conclusion that there is an approximate 40-yr difference between Southern Hemisphere (SH) data and the standard calibration, with significant real variability. The consistency of our results relative to IntCal04 and the work of Hogg and McCormac supports the suggested 40-yr offset for general SH calibration. Higher-precision calibrations that take advantage of curve-matching will also require a hemispherespecific calibration curve.

\section{CONCLUSIONS AND FURTHER WORK}

Temporal variability in the offset between the Northern and Southern hemispheres appears to be a real feature of the history of the atmospheric ${ }^{14} \mathrm{C}$ system, as evidenced by previous studies, and suggested by the variability of the Tasmanian pine data reported here compared with IntCal04. In order to examine the variability in our record for possible periodicity, several periods need to be repli- 
cated, in particular between 1095 and $1175 \mathrm{yr} \mathrm{BP}$, where the apparent offset of the Tasmanian data appears to reduce to zero. The similarities and differences in detail between these Huon data and other Southern Hemisphere data sets will establish an extended calibration curve for Southern Hemisphere dates, and may further illuminate the question of the size and periodicity of the interhemispheric offset found previously by Hogg and McCormac (Hogg et al. 2002; McCormac et al. 2002).

\section{ACKNOWLEDGMENTS}

Many thanks to Paula Zermeño, Kate Dydak, and Dean Reese for assistance in sample preparation. We particularly thank Dave Mucciarrone of the Stanford Stable Isotope Laboratory. The Belfast cellulose sample and the Q1323 wood was kindly provided by Gerry McCormac and Paula Reimer, Queen's University Belfast. This work was performed under the auspices of the US Department of Energy by Lawrence Livermore National Laboratory in part under Contract W-7405-Eng-48 and in part under Contract DE-AC52-07NA27344.

\section{REFERENCES}

Buckley BM, Cook ER, Peterson MJ, Barbetti M. 1997. A changing temperature response with elevation for Lagarostrobos franklinii in Tasmania, Australia. Climatic Change 36(3-4):477-98.

Hogg AG, McCormac FG, Higham TFG, Reimer PJ, Bailie MGL, Palmer JG. 2002. High-precision radiocarbon measurements of contemporaneous tree-ring dated wood from the British Isles and New Zealand: AD 1850-950. Radiocarbon 44(3):633-40.

McCormac FG, Hogg AG, Higham TFG, Lynch-Stieglitz J, Broecker WS, Baillie MGL, Palmer J, Xiong L, Pilcher J, Brown D, Hoper ST. 1998. Temporal variation in the interhemispheric ${ }^{14} \mathrm{C}$ offset. Geophysical Research Letters 25(9):1321-4.

McCormac FG, Reimer PJ, Hogg AG, Higham TFG, Bailie MGL, Palmer JG, Stuiver M. 2002. Calibration of the radiocarbon time scale for the Southern Hemisphere: AD 1850-950. Radiocarbon 44(3):641-51.

Pearson GW, Pilcher JR, Bailie MGL, Corbett DM, Qua F. 1986. High-precision ${ }^{14} \mathrm{C}$ measurement of Irish oaks to show the natural ${ }^{14} \mathrm{C}$ variations from $\mathrm{AD} 1840$ to 5210 BC. Radiocarbon 28(2B):911-34.
Reimer PJ, Baillie MGL, Bard E, Bayliss A, Beck JW, Bertrand CJH, Blackwell PG, Buck CE, Burr GS, Cutler KB, Damon PE, Edwards RL, Fairbanks RG, Friedrich M, Guilderson TP, Hogg AG, Hughen KA, Kromer B, McCormac G, Manning S, Bronk Ramsey C, Reimer RW, Remmele S, Southon JR, Stuiver M, Talamo S, Taylor FW, van der Plicht J, Weyhenmeyer CE. 2004. IntCal04 terrestrial radiocarbon age calibration, 0-26 cal kyr BP. Radiocarbon 46(3):1029-58.

Stuiver M, Braziunas TF 1998. Anthropogenic and solar components of hemispheric ${ }^{14} \mathrm{C}$. Geophysical Research Letters 25(3):329-32.

Stuiver M, Polach HA 1977. Discussion: reporting of ${ }^{14} \mathrm{C}$ data. Radiocarbon 19(3):355-63.

Vogel JC, Fuls A, Visser E, Becker B. 1993. Pretoria calibration curve for short-lived samples, 1930-3350 BC. Radiocarbon 35(1):73-85.

Vogel JS, Southon JR, Nelson DE, Brown TA. 1984. Performance of catalytically condensed carbon for use in accelerator mass spectrometry. Nuclear Instruments and Methods in Physics Research B 5(2):289-93. 